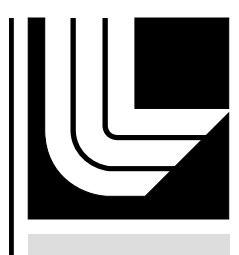

LAW RENCE LIVERMORE N A T IO N A L LABORATORY

\title{
UCRL-TR-209935
}

\section{Thoughts on VCD-145 Detector Calibration}

W. V. Morgan

February 24, 2005 
This document was prepared as an account of work sponsored by an agency of the United States Government. Neither the United States Government nor the University of California nor any of their employees, makes any warranty, express or implied, or assumes any legal liability or responsibility for the accuracy, completeness, or usefulness of any information, apparatus, product, or process disclosed, or represents that its use would not infringe privately owned rights. Reference herein to any specific commercial product, process, or service by trade name, trademark, manufacturer, or otherwise, does not necessarily constitute or imply its endorsement, recommendation, or favoring by the United States Government or the University of California. The views and opinions of authors expressed herein do not necessarily state or reflect those of the United States Government or the University of California, and shall not be used for advertising or product endorsement purposes.

This work was performed under the auspices of the U.S. Department of Energy by University of California, Lawrence Livermore National Laboratory under Contract W-7405-Eng-48. 


\title{
Thoughts on VCD-145 Detector Calibration (U)
}

\author{
Walter V. Morgan \\ Lawrence Livermore National Laboratory
}

3 February 2005

\section{A. Objectives and Sources}

In 1980, Don Smith requested that the EG\&G Detector Group in North Las Vegas provide a summary of calibrated sensitivities for the VCD-145 detector. The desired information was provided in a memorandum from Sam Egdorf (Reference 1). A memo from Brent Davis issued a week later described the effect on VCD-145 detector sensitivity that resulted from changing the thickness of the stainless steel entrance window (Reference 2). This memo is intended first to effectively archive those two references, and second to record thoughts about the significance of their contents.

Reference 1 lists a total of 118 calibrated values for 80 different VCD-145 detectors, from 1977 to 1980 . With only four exceptions, all of the serial numbers from V004 to V087 were included. The earlier calibrations were for detectors with 1-mil entrance windows, and the later ones were for detectors with 2-mil entrance windows. ${ }^{1}$ Three of the earlier units were calibrated at both thicknesses by temporarily placing an extra 1-mil sheet of stainless steel across the window. Altogether six different collimator diameters were used, from $60 \mathrm{~mm}$ to $95 \mathrm{~mm}$. Some units were calibrated for more than one collimator diameter, and 14 were at some point designated as backup detectors for a second event.

Reference 2 describes the effect of window thickness on calibrated sensitivity. Quoting that reference:

To demonstrate that the sensitivity decrease is solely a function of the window thickness, a standard VCD-145 detector with a 0.001-inch thick window was calibrated with the ${ }^{60}$ Co source. Then without changing detector or geometry, a 0.001 -inch thick stainless steel foil (same material as that of the window) was placed directly in front of the detector window, effectively making a 0.002-inch thick entrance window. The detector was again calibrated. This technique was repeated until the detector had an entrance window equivalent to 0.010-inches thick.

\footnotetext{
${ }^{1}$ The change from 1-mil to 2-mil stainless steel entrance window was made for cost and reliability purposes. The 1-mil thickness was difficult to weld, and more likely to fail in the field. Both were very thin compared to the entrance windows of earlier model vacuum Compton detectors: the VCD-125, VCD127 and VCD-129 all used 60-mil thick silver entrance windows. With the new, thin windows, it was necessary to provide magnets on either side of the beam, between the collimator exit and the detector, to eliminate charged particles.
} 


\section{B. The Data}

Reference 1. The data given in Reference 1 were entered into an Excel spreadsheet, and sorted by chronologic sequence and by collimator diameter. The results were saved as two spreadsheets, References 3 and 4, respectively, and either of those can be used to do further sorting. A three-page image of Reference 3 is included here as Table I. A three-page image of Reference 4 is included here as Table II. Both tables include averages for various subsets of the data, and at the end of Table II is a statistical summary of trends due to collimator diameter and entrance window thickness. The sensitivity values are all presented with $1.0 \mathrm{E}-22 \mathrm{C} / \mathrm{G}-\mathrm{MeV}$ suppressed, and that same convention will be used in the discussion that follows. A sensitivity given as 2.95 , for example, implies an actual sensitivity of $2.95 \mathrm{E}-22 \mathrm{C} / \mathrm{G}-\mathrm{MeV}$.

Reference 2 presented data in the form of a hand-drawn plot. The ten data points from that plot have now been extracted for presentation in Figure 1. The smooth curve is a fourth-order fit to the data, an approximation of the hand-drawn curve in the plot of Reference 2.

\section{Observations - Collimator Diameter}

Referring to the tabulations at the end of Table II, it is not apparent that there is a trend in sensitivity due to changing diameter (for either window thickness): the standard deviations are rather large compared to the differences. A somewhat different picture emerges when comparisons are made for the 20 individual detectors that were calibrated at both $60-\mathrm{mm}$ and 80 $\mathrm{mm}$ diameters. Subtracting the sensitivity at $60-\mathrm{mm}$ from that at $80-\mathrm{mm}$ for the 20 individual detectors, the following changes are found:
0.01 decrease
four detectors
0.00 change
one detector
0.01 increase
nine detectors
0.02 increase
six detectors
0.04 increase
one detector

Note that 0.01 sensitivity unit is of the order of one part in 300 , since the sensitivities are about 3 . One detector, V022, was calibrated at both diameters in both 1979 and 1980, leading to a total of 21 comparison pairs.

From this histogram-type comparison, it is reasonable to infer that sensitivity at $80 \mathrm{~mm}$ is something more than 0.01 unit greater than at $60 \mathrm{~mm}$, or perhaps one-half percent.

\section{Observations - Window Thickness}

From Figure 1, data obtained using one specific detector, we find that the sensitivity with a 2-mil window was $91.6 \%$ of that with a 1 -mil window. (Some small uncertainty must be associated with that value because of the limited precision with which calibrated sensitivity is reported. Using the values for the $4^{\text {th }}$ order fit at 1-mil and 2-mil, the ratio becomes $91.9 \%$.) A summary at the end of Table II shows that for the data from Reference 1, 2-mil sensitivity is about $90 \%$ to $93 \%$ of the 1-mil sensitivity, perhaps depending somewhat on the collimated diameter. This is completely consistent with the data from Reference 2 (Figure 1). (Reference 2 did not state what collimator diameter was used in obtaining that data, but it would certainly have been at least 80 $\mathrm{mm}$.) 


\section{E. A Window-current/Emitter-current Model}

In the calibration procedure using the ${ }^{60} \mathrm{Co}$ source, currents of opposite polarity are produced by photons incident on the window and on the emitter. Since the emitter (3/16-inch aluminum) is much thicker, it produces the much larger current. As the window thickness is increased, the emitter current remains essentially constant, but the window current increases, so the calibrated sensitivity - the difference in the window and emitter currents - decreases. This explanation is completely consistent with the data presented in Reference 2 . The same trend is also evident in Reference 1 data.

For the VCD-145 detector, the spacing from the window to the center of the emitter is $74 \mathrm{~mm}$, or about 1/4 nanosecond at the speed of light. Thus, it would be expected that the negative current from the front window would be produced about one-quarter nanosecond before the emitter current, and, indeed, transforms obtained with the Santa Barbara linear accelerator show that a negative precursor is present at about that relative time. The static and dynamic situations are both fully consistent with the concept of detector currents of opposite polarity from the front window and emitter.

The window current is electrons leaving the window and hitting the emitter. Other electrons leaving the window may miss the emitter, but they don't count because they must then somehow be intercepted by the detector case - which is electrically identical to the window. As collimator diameter is reduced, both emitter and window currents will decrease, but the efficiency of the window current will increase because the solid angle presented by the emitter to the window is increased. Thus, for smaller collimator diameters the calibrated sensitivity would be expected to decrease. This is consistent with the observations in Section $\mathrm{C}$ above.

In the dynamic case, a larger window current - relative to the emitter current - will mean a larger negative precursor. Whereas a smaller collimator or thicker window will statically reduce the detector sensitivity, the dynamic consequence of increased negative precursor accompanying the same changes is much more serious.

\section{F. Calibration Repeatability}

It has normally been assumed that detector calibrations are repeatable to $+/-0.01$ sensitivity units, which is also the precision used in reporting. To test that, data from Reference 1 were searched for calibrations repeated for a given detector at a given collimation. Seven pairs were found for six different detectors, with the repeat calibrations following by six to nine months. The windows for all of these were the 1-mil thickness. The changes found:
0.05 decrease
one measurement pair ( $80 \mathrm{~mm}$ collimation)
0.02 decrease*
one measurement pair ( $80 \mathrm{~mm}$ collimation)
0.01 decrease
one measurement pair ( $80 \mathrm{~mm}$ collimation)
0.01 increase* $^{*}$
two measurement pairs (both $60 \mathrm{~mm}$ collimation)
0.02 increase
two measurement pairs (both $80 \mathrm{~mm}$ collimation)

This is a very small statistical sample, but my initial inference is that it implies that the calibrated sensitivity has a one-sigma uncertainty of about 0.02 units. If a much more comprehensive experiment were performed (and it is possible that this has already been done), almost certainly 
the standard deviation would be at least 0.01 units, for the precision is 0.01 , and in the limited sample here, none of the pairs gave a zero change.

Differences obtained for the calibrated sensitivity for a given detector must be due either to changes in the detector or to random errors associated with the calibration process. If a detector were to be calibrated 10 times in a given day, we would certainly not expect the simple, passive detector to have changed, and differences would be considered a measure of the accuracy of the calibration process. If the detector were to be calibrated once in each of 10 successive months, it still seems unlikely that the simple, passive detector has changed, so differences would still likely be assigned to the calibration process - but indicating long-term drift-type problems instead of short-term problems.

Further evidence of the randomness of the sample above is the fact that the detector that was given repeat calibrations at two diameters (V022) fell in the two groups above that are starred: the 0.02 decrease and the 0.01 increase.

\section{G. Unit-to-unit Sensitivity Differences}

It had long puzzled me why the calibrated sensitivities within a set of presumably identical, simple, passive vacuum Compton detectors were not all the same, even though different units were calibrated at the same collimation. Since it has been observed that there is a pronounced change in sensitivity with window thickness, a plausible answer might be found there. Brent Davis has informed me that the stainless steel windows for these detectors did not have a thickness specification; only a nominal 1-mil or 2-mil thickness requirement was given to the vendor. It is plausible, then, that the actual thickness used could be different from the nominal by perhaps $5 \%$, and that value will be used for purposes of a simple trend calculation. The mean sensitivity for 1-mil and 2-mil windows (from Reference 2) is 2.98 (the sensitivity multiplier of $1.0 \mathrm{E}-22 \mathrm{C} / \mathrm{G}-\mathrm{MeV}$ will continue to be understood), and the slope is negative 0.26 per mil, or

Sensitivity $=-0.26 \mathrm{dT}+2.98$

where dT is the change, in mils, from the mean window thickness of 1.5 mils $(0.0015 \mathrm{inch})$.

Letting dT be $+/-0.5$ mils gives just the reported sensitivities of 3.11 (1-mil window) and 2.85 (2-mil window). A $5 \%$ variation in nominal thickness would lead to dT of -0.45 to -0.55 mils for the nominal 1 -mil window, and +0.4 to +0.6 mils for the nominal 2 -mil window. Using the equation above for sensitivity versus change in window thickness, the resulting plausible sensitivity ranges are:

1-mil windows: 3.097 to 3.123

2-mil windows: 2.876 to 2.824

$$
\begin{array}{ll}
\text { or } 3.11+/-0.013 & \text { [or }+/-0.42 \%] \\
\text { or } 2.85+/-0.026 & \text { [or }+/-0.91 \%]
\end{array}
$$

Using the data at the end of Table II for window and collimator diameter combinations that have 10 or more samples, the standard deviations were found to range from 0.017 to 0.043 . These values are reasonably consistent with the simple numerical analysis above that looks at the trend of sensitivity with window thickness. The assumption of a possible 5\% variation in thickness was rather arbitrary. No information is available as to actual window thickness variations.

It is concluded that the minor sensitivity variations reported for various units of a given type of vacuum Compton detector should be considered to be meaningful. However, it is possible that 
window thickness variation is no more significant than the variation due to calibration uncertainty, as discussed in Section F.

\section{H. Conclusions}

There are multiple reasons to suspect that the accuracy of the sensitivity reported for a vacuum Compton detector is uncertain by one-half percent or so. Differences in collimated diameter, variations in window thickness, and unknown errors in the calibration procedures all seem to have some small uncertainty. If one looks at the situation from another angle, this can be considered good news - because there are no indications of uncertainties at the one percent level. Having studied the data from References 1 and 2 in depth, it is my opinion that an experimenter can be confident that the calibrated sensitivity reported for a vacuum Compton detector is accurate to one percent or better. This may not be the smallest error in a reaction history measurement, and it may not be negligible, but realistically it is not often a concern. The uncertainty in knowledge of energy transmission through several mean free paths of attenuating material will almost certainly be several times larger than the uncertainty in detector sensitivity.

It is believed that there is a trend for the VCD-145 sensitivity to decrease as the collimator diameter is reduced. Since this likely aggravates the problem of the negative precursor, it is recommended that when detector time response is important, the detector should only be used with a collimator that is close to the largest allowed.

\section{Addendum -- The VCD-146 Detector}

Within a few years after References 1 and 2 were written, a new, smaller, faster version of the VCD-145 detector became available, and it was designated the VCD-146. The VCD-145 was compatible with collimators as large as $100-\mathrm{mm}$ diameter; the VCD-146 was designed for collimators no larger than 50-mm diameter. A goal with this entire series of detectors, beginning at least with the VCD-129, was to maintain 50 ohms impedance through the detector. Perhaps the VCD-146 did this somewhat better than the others, but it is believed that its smaller size and thinner entrance window were more important. The 1-mil stainless steel window, desirable because a smaller negative precursor would result, was found to be sufficiently reliable for the VCD-146 detector because of its much smaller span. The smaller diameter also meant a tighter geometric distribution of photon/electron events on the emitter, resulting in a tighter distribution of travel times to a common point on the coaxial jumper cable.

\section{References:}

1. EG\&G/LVO memo RES 11; S. Egdorf to D. E. Smith; 12 June 1980.

2. EG\&G/LVO Technical Bulletin DESSD-E-017; B. A. Davis, 18 June 1980.

3. Excel worksheet VCD145_Sensitivity_Chrono; W. Morgan; 31 January 2005

4. Excel worksheet VCD145_Sensitivity_Coll; W. Morgan; 31 January 2005 
TABLE I (page 1 of 3)

VCD-145 Calibration Data - Sorted Chronologically

\begin{tabular}{|c|c|c|c|c|c|c|c|c|c|c|c|}
\hline Memo & Event name & Manth & Year & Type & Serial & Collimator & \multicolumn{2}{|c|}{ Sensitivity } & Avg & Avg. & NOTE \\
\hline entry & & & & name & Number & diameter & $1-\mathrm{mil}$ & 2-mil & sens. & sens. & \\
\hline sequence & & & & (as in memo) & & $(\mathrm{mm})$ & $(e-22)$ & $(e-22)$ & $1-\mathrm{mil}$ & $2-\mathrm{mil}$ & \\
\hline 1 & FARALLONES & 12 & 1977 & VCD-145M & Voo4 & 75 & 3.26 & & & & \\
\hline 2 & FARALLONES & 12 & 1977 & VCD-145M & Voos & 75 & 3.24 & & & & \\
\hline 3 & FARALLONES & 12 & 1977 & VCD-145M & Yoos & 75 & 2.81 & & & & 1 \\
\hline 4 & FARALLONES & 12 & 1977 & VCD-145M & Yo06 & 75 & 3.24 & & & & \\
\hline 5 & FARALLONES & 12 & 1977 & VCD-145M & Yoo7 & 75 & 3.24 & & & & \\
\hline 6 & FARALLONES & 12 & 1977 & $V C D-145 \mathrm{M}$ & Voos & 75 & 3.26 & & 3.2543 & & $\pi 3$ \\
\hline 7 & FARALLONES & 12 & 1977 & VCD-145M & Yoog & 75 & 3.28 & & & & \\
\hline$B$ & FARALLONES & 12 & 1977 & VCD-145M & Vo10 & 75 & 3.26 & & & & \\
\hline 9 & REBLOCHON & 3 & 1978 & $V C D-145 M$ & V011 & 75 & 3.28 & & & & \\
\hline 10 & REBLOCHON & 3 & 1978 & YCD-145M & Vo12 & 75 & 3.28 & & 3.280 & & \\
\hline 11 & REBLOCHON & 3 & 1978 & VCD-1 45M & V013 & 75 & 3.28 & & & & \\
\hline 12 & CAMPOS & 3 & 1978 & VCD-145M & Vo09 & 80 & 3.25 & & & & \\
\hline 13 & CAMPOS & 3 & 1978 & VCD-145M & Vo10 & 80 & 3.24 & & 3.2433 & & \\
\hline 14 & CAMPOS & 3 & 1978 & YCD-145M & Vo14 & 80 & 3.24 & & & & \\
\hline 15 & PANIR & 9 & 1978 & VCD-145M & V014 & 60 & 3.18 & & & & \\
\hline 16 & PANIR & 9 & 1978 & VCD-1 45M & Vo14 & 80 & 3.19 & & & & \\
\hline 17 & PANIR & 9 & 1978 & VCD-145M & Y015 & 60 & 3.14 & & & & \\
\hline 18 & PANIR & 9 & 1978 & VCD-145M & Yo15 & 80 & 3.16 & & & & \\
\hline 19 & PANIR & 9 & 1978 & $V C D-145 M$ & V016 & 60 & 3.18 & & & & \\
\hline 20 & PANIR & 9 & 1978 & VCD-1 45M & V016 & 80 & 3.19 & & & & \\
\hline 21 & PANIR & 9 & 1978 & VCD-145M & Y017 & 60 & 3.18 & & & & \\
\hline 22 & PANIR & 9 & 1978 & VCD-145M & Vo17 & 80 & 3.19 & & & & \\
\hline 23 & PANIR & 9 & 1978 & $\mathrm{VCD}-145 \mathrm{M}$ & Vo1B & 60 & 3.18 & & & & \\
\hline 24 & PANIR & 9 & 1978 & VCD-145M & Vo18 & 80 & 3.19 & & 3.2042 & & \\
\hline 25 & PANIR & 9 & 1978 & VCD-145M & Y019 & 60 & 3.18 & & & & \\
\hline 26 & PANIR & 9 & 1978 & VCD-145M & Yo19 & 80 & 3.19 & & & & \\
\hline 27 & PANIR & 9 & 1978 & VCD-145M & Yo23 & 60 & 3.18 & & & & \\
\hline 28 & PANIR & 9 & 1978 & $V C D-145 M$ & vo23 & 80 & 3.19 & & & & \\
\hline 29 & PANIR & 9 & 1978 & VCD-145M & V024 & 60 & 3.27 & & & & \\
\hline 30 & PANIR & 9 & 1978 & VCD-145M & Vo24 & 80 & 3.26 & & & & \\
\hline 31 & PANIR & 9 & 1978 & VCD-145M & Yo27 & 80 & 3.24 & & & & \\
\hline 32 & IPANIR & 9 & 1978 & VCD-145M & Vo28 & 80 & 3.22 & & & & \\
\hline 33 & PANIR & 9 & 1978 & VCD-145M & Vo29 & 80 & 3.21 & & & & \\
\hline 34 & PANIR & 9 & 1978 & VCD-145M & Yo30 & 80 & 3.22 & & & & \\
\hline 35 & PANIR & 9 & 1978 & VCD-145M & Yo31 & 80 & 3.22 & & & & \\
\hline 36 & PANIR & 9 & 1978 & $V C D-145 M$ & Yo32 & 80 & 3.22 & & & & \\
\hline 37 & PANIR & 9 & 1978 & VCD-145M & Vo33 & 80 & 3.22 & & & & \\
\hline 38 & PANIR & 9 & 1978 & VCD-145M & Yo34 & 80 & 3.30 & & & & \\
\hline 39 & DIABLO HAWK & 10 & 1978 & VCD-145M & Yo20 & 60 & 3.22 & & & & \\
\hline 40 & DIABLO HALNK & 10 & 1978 & VCD-145M & vo20 & 80 & 3.21 & & & & \\
\hline 41 & DIABLOO HAWNK & 10 & 1978 & VCD-145M & Yo22 & 60 & 3.22 & & & & \\
\hline 42 & DIABLO HAWK & 10 & 1978 & $V C D-145 M$ & Vo22 & 80 & 3.24 & & 3.2175 & & \\
\hline 43 & DIABLO HANNK & 10 & 1978 & VCD-145M & Yo25 & 60 & 3.20 & & & & \\
\hline 44 & DIABLO HAWK & 10 & 1978 & VCD-145M & Yo25 & 80 & 3.21 & & & & \\
\hline 45 & DIABLO HAWK & 10 & 1978 & VCD-145M & Yo26 & 60 & 3.22 & & & & \\
\hline 46 & DIABLO HAMYK & 10 & 1978 & VCD-145M & Y026 & 80 & 3.22 & & & & \\
\hline
\end{tabular}


TABLE I (page 2 of 3) VCD-145 Calibration Data - Sorted Chronologically

\begin{tabular}{|c|c|c|c|c|c|c|c|c|c|c|c|}
\hline Memo & Event name & Month & Year & Type & Serial & Collimator & \multicolumn{2}{|c|}{ Sensitivity } & Avg & Avg. & NOTE \\
\hline entry & & & & name & Number & diameter & 1-mil & 2 -mil & sens. & sens. & \\
\hline sequence & & & & (as in memo) & & $(\mathrm{mm})$ & $(e-22)$ & $(e-22)$ & $1-\mathrm{mil}$ & $2-\mathrm{mil}$ & \\
\hline 47 & QUJARGEL & 11 & 1978 & $Y C D-145 M$ & Y035 & 80 & 3.18 & & & & \\
\hline 48 & QUARGEL & 11 & 1978 & VCD-145M & Vo36 & 80 & 3.22 & & & & \\
\hline 49 & QUARGEL & 11 & 1978 & VCD-145M & V037 & 80 & 3.20 & & 3.180 & & $* 1$ \\
\hline 50 & QUARGEL & 11 & 1978 & VCD-145M & Yo38 & 80 & 3.18 & & 3.196 & & \\
\hline 51 & QUARGEL & 11 & 1978 & VCD-145M & Y039 & 80 & 3.20 & & & & \\
\hline 52 & QUARGEL & 11 & 1978 & VCD-145M & V039 & 90 & 3.10 & & & & 3 \\
\hline 53 & FARM & 12 & 1978 & VCD-145M & Y040 & 80 & 3.18 & & & & \\
\hline 54 & FARM & 12 & 1978 & VCD-145M & Yo41 & 80 & 3.15 & & & & \\
\hline 55 & FARM & 12 & 1978 & VCD-145M & Y042 & 80 & 3.18 & & & & \\
\hline 56 & FARM & 12 & 1978 & YCD-145M & $\mathrm{V} 043$ & 80 & 3.20 & & & & \\
\hline 57 & FARM & 12 & 1978 & VCD-145M & Vo44 & 80 & 3.16 & & 3.172 & & \\
\hline 58 & FARM & 12 & 1978 & VCD-145M & Y045 & 80 & 3.20 & & & & \\
\hline 59 & FARM & 12 & 1978 & YCD-145M & Y046 & 80 & 3.16 & & & & \\
\hline 60 & FARM & 12 & 1978 & VCD-145M & V047 & 80 & 3.16 & & & & \\
\hline 61 & FARM & 12 & 1978 & VCD-145M & Vo4g & 80 & 3.16 & & & & \\
\hline 62 & KLOSTER & 2 & 1979 & VCD-145M & Y050 & 60 & 3.14 & & & & \\
\hline 63 & KL OSTER & 2 & 1979 & YCD-145M & Y050 & 80 & 3.13 & & & & \\
\hline 64 & KLOSTER & 2 & 1979 & VCD-145M & Yo51 & 60 & 3.11 & & & & \\
\hline 65 & KLOSTER & 2 & 1979 & VCD-145M & V051 & 80 & 3.13 & & 3.140 & & \\
\hline 66 & KLOSTER & 2 & 1979 & VCD-145M & vos2 & 60 & 3.13 & & & & \\
\hline 67 & KLOSTER & 2 & 1979 & VCD-145M & Yo52 & 80 & 3.14 & & & & \\
\hline 68 & KLOSTER & 2 & 1979 & YCD-1 $45 M$ & Y053 & 60 & 3.16 & & & & \\
\hline 69 & KLOSTER & 2 & 1979 & VCD-145M & V053 & 80 & 3.18 & & & & \\
\hline 70 & PEPATO & 6 & 1979 & VCD-145M & Vo22 & 80 & 3.22 & & & & \\
\hline 71 & PEPATO & 6 & 1979 & VCD-1 45M & V022 & 60 & 3.23 & & 3.233 & & \\
\hline 72 & PEPATO & 6 & 1979 & VCD-145M & V024 & 60 & 3.28 & & & & \\
\hline 73 & PEPATO & 6 & 1979 & VCD-145M & Yo25 & 80 & 3.20 & & & & \\
\hline 74 & BURZET & $\overline{8}$ & 1979 & VCD-145M & Y042 & 80 & 3.20 & & & & \\
\hline 75 & BURZET & 8 & 1979 & VCD-145M & V055 & 80 & 3.20 & & 3.197 & & \\
\hline 76 & BURZET & 8 & 1979 & VCD-145M & Y056 & 80 & 3.19 & & & & \\
\hline 77 & PERA & 9 & 1979 & YCD-145M-1 & Y053 & 80 & 3.20 & & 3.20 & & \\
\hline 78 & NESSEL & 9 & 1979 & $Y C D-145-2 M$ & V060 & 80 & & 2.88 & & & \\
\hline 79 & NESSEL & 9 & 1979 & VCD-145-2M & Vo61 & 80 & & 2.90 & & & \\
\hline 80 & NESSEL & 9 & 1979 & VCD-145-2M & Y062 & 80 & & 2.89 & & & \\
\hline 81 & NESSEL & 9 & 1979 & VCD-145-2M & Vo63 & 80 & & 2.88 & & 2.914 & \\
\hline 82 & NESSEL & 9 & 1979 & VCD-145-2M & Vo64 & 80 & & 2.97 & & & \\
\hline 83 & NESSEL & 9 & 1979 & VCD-145-2M & V065 & 80 & & 2.95 & & & \\
\hline 84 & NESSEL & 9 & 1979 & YCD-145-2M & Yos6 & 80 & & 2.93 & & & \\
\hline 85 & AZUL & 12 & 1979 & VCD-145-2M & Vo58 & 90 & & 2.85 & & & \\
\hline $8 \overline{6}$ & AZUL & 12 & 1979 & YCD-145-2M & Vo59 & 90 & & 2.85 & & & \\
\hline 87 & TARKO & 2 & 1980 & VCD-145-2M & V068 & 80 & & 2.95 & & & \\
\hline 88 & TARKO & 2 & 1980 & $V C D-145-2 M$ & Yo71 & 80 & & 2.95 & & 2.940 & \\
\hline 89 & TARKO & 2 & 1980 & VCD-145-2M & Vo72 & 80 & & 2.93 & & & \\
\hline 90 & TARKO & 2 & $19 \overline{80}$ & VCD-145-2M & vor4 & 80 & & 2.93 & & & \\
\hline 91 & NORBO & 3 & 1980 & VCD-145-2M & V013 & 60 & & 2.90 & & & \\
\hline 92 & NORBO & 3 & 1980 & VCD-145-2M & Yo17 & 60 & & 2.88 & & & \\
\hline
\end{tabular}


TABLE I (page 3 of 3 )

VCD-145 Calibration Data - Sorted Chronologically

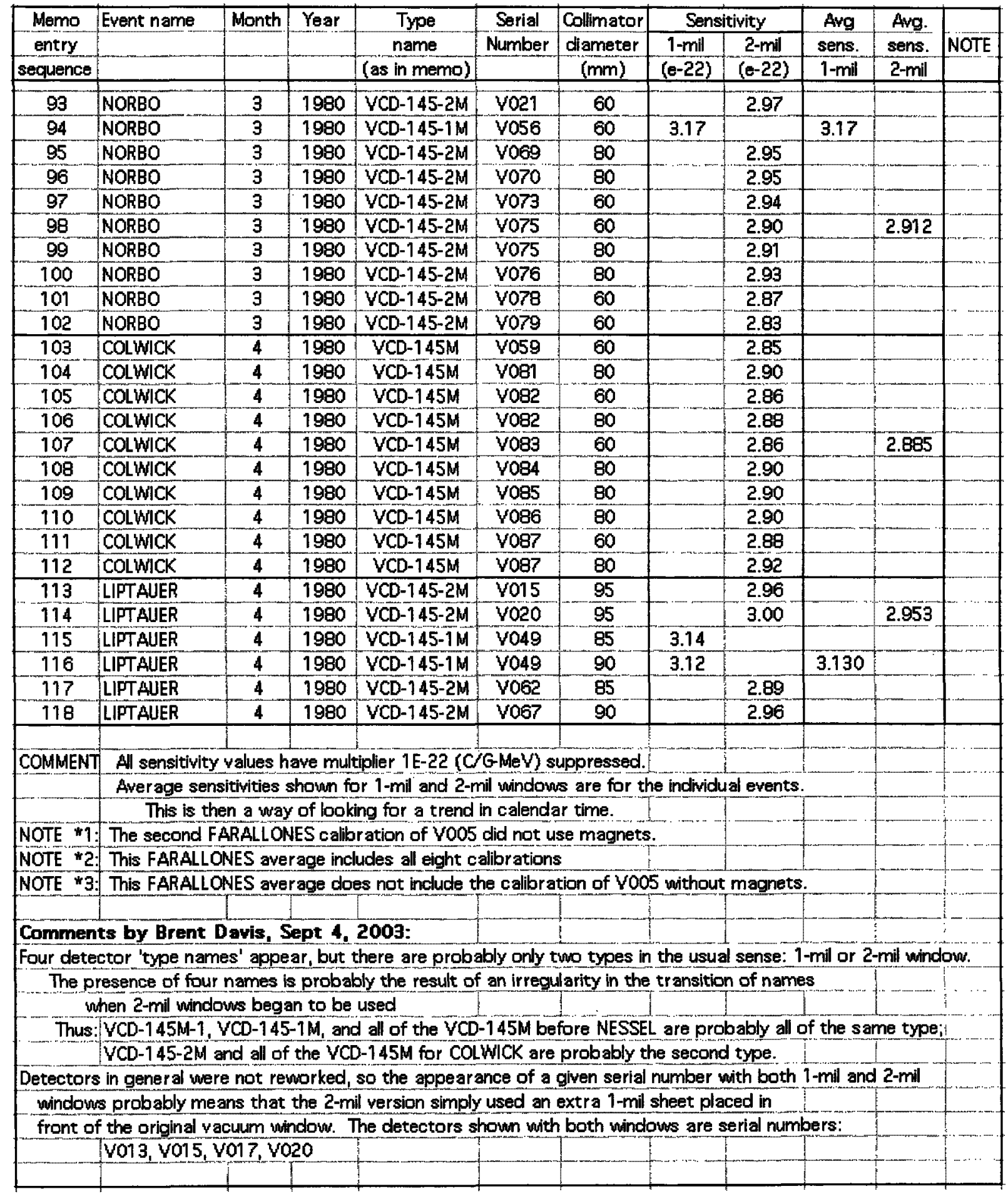


TABLE II (page 1 of 3)

VCD-145 Calibration Data - Sorted by Collimator Diameter

\begin{tabular}{|c|c|c|c|c|c|c|c|c|c|}
\hline Memo & Event name & Month & Year & Type & Serial & Collimator & \multicolumn{2}{|c|}{ Sensitivity } & \\
\hline entry & & & & name & Number & diameter & 1-mil & 2-mil & Average \\
\hline sequence & & & & (as in memo) & & $(\mathrm{mm})$ & $(e-22)$ & $(e-22)$ & \\
\hline 3 & FARALLONES & 12 & 1977 & VCD-145M & Yo05 & 75 & 289 & & NOTE*1 \\
\hline 15 & PANIR & 9 & 1978 & VCD-145M & V014 & 60 & 3.18 & & \\
\hline 17 & PANIR & 9 & 1978 & VCD-145M & Y015 & 60 & 3.14 & & \\
\hline 19 & PANIR & 9 & 1978 & VCD-145M & V016 & 60 & 3.18 & & \\
\hline 21 & PANIR & 9 & 1978 & VCD-145M & V017 & 60 & 3.18 & & \\
\hline 23 & PANIR & 9 & 1978 & VCD-145M & Y018 & 60 & 3.18 & & \\
\hline 25 & PANIR & 9 & 1978 & VCD-145M & Y019 & 60 & 3.18 & & \\
\hline 27 & PANIR & 9 & 1978 & VCD-145M & V023 & 60 & 3.18 & & \\
\hline 29 & PANIR & 9 & 1978 & VCD-145M & Y024 & 60 & 3.27 & & \\
\hline 39 & DIABLO HAWK & 10 & 1978 & VCD-145M & Yo20 & 60 & 3.22 & & \\
\hline 41 & DIABLO HAWK & 10 & 1978 & YCD-145M & Y022 & 60 & 3.22 & & 3.19 \\
\hline 43 & DIABLO HAWK & 10 & 1978 & YCD-145M & Yoè & 60 & 3.20 & & $(60-\mathrm{mm})$ \\
\hline 45 & DIABLO HAWK & 10 & 1978 & YCD-145M & Yo26 & 60 & 3.22 & & \\
\hline 62 & KLOSTER & 2 & 1979 & YCD-145M & V050 & 60 & 3.14 & & \\
\hline 64 & KLOSTER & 2 & 1979 & VCD-145M & Y051 & 60 & 3.11 & & \\
\hline 66 & KLOSTER & 2 & 1979 & YCD-145M & Y052 & 60 & 3.13 & & \\
\hline 68 & KLOSTER & 2 & 1979 & VCD-145M & Y053 & 60 & 3.16 & & \\
\hline 71 & PEPATO & 6 & 1979 & VCD-145M & V022 & 60 & 3.23 & & \\
\hline 72 & PEPATO & 6 & 1979 & VCD-145M & Y024 & 60 & 3.28 & & \\
\hline 94 & NORBO & 3 & 1980 & VCD-145-1M & V056 & 60 & 3.17 & & \\
\hline 1 & FARALLONES & 12 & 1977 & VCD-145M & YoO4 & 75 & 3.26 & & \\
\hline 2 & FARALLONES & 12 & 1977 & VCD-145M & Yoos & 75 & 3.24 & & \\
\hline 4 & FARALLONES & 12 & 1977 & VCD-145M & V006 & 75 & 3.24 & & \\
\hline 5 & FARALLONES & 12 & 1977 & VCD-145M & Yoor & 75 & 3.24 & & \\
\hline 6 & FARALLONES & 12 & 1977 & VCD-145M & Yoos & 75 & 3.26 & & \\
\hline 7 & FARALLONES & 12 & 1977 & VCD-145M & Yoog & 75 & 3.28 & & 3.26 \\
\hline 8 & FARALLONES & 12 & 1977 & VCD-145M & V010 & 75 & 3.26 & & $(75-m m)$ \\
\hline 9 & REBLOCHON & 3 & 1978 & VCD-145M & vol1 & 75 & 3.28 & & \\
\hline 10 & REBLOCHON & 3 & 1978 & VCD-145M & Y012 & 75 & 3.28 & & \\
\hline 11 & REBLOCHON & 3 & 1978 & VCD-145M & Yo13 & 75 & 3.28 & & \\
\hline 12 & CAMPOS & 3 & 1978 & $V C D-145 M$ & Yo09 & 80 & 3.25 & & \\
\hline 13 & CAMPOS & 3 & 1978 & $V C D-145 M$ & V010 & 80 & 3.24 & & \\
\hline 14 & CAMPOS & 3 & 1978 & VCD-145M & Vo14 & 80 & 3.24 & & \\
\hline 16 & PANIR & 9 & 1978 & VCD-145M & V014 & 80 & 3.19 & & \\
\hline 18 & PANIR & 9 & 1978 & VCD-145M & Yo15 & 80 & 3.16 & & \\
\hline 20 & PANIR & 9 & 1978 & $V C D-145 M$ & Y016 & 80 & 3.19 & & \\
\hline 22 & PANIR & 9 & 1978 & VCD-145M & Vol7 & 80 & 3.19 & & \\
\hline 24 & PANIR & 9 & 1978 & VCD-145M & Vo18 & 80 & 3.19 & & \\
\hline 26 & PANIR & 9 & 1978 & VCD-145M & Volg & 80 & 3.19 & & \\
\hline 28 & PANIR & 9 & 1978 & VCD-145M & Vo23 & 80 & 3.19 & & \\
\hline 30 & PANIR & 9 & 1978 & $\checkmark C D-145 M$ & Vo24 & 80 & 3.26 & & \\
\hline 31 & PANIR & 9 & 1978 & VCD-145M & vo27 & 80 & 3.24 & & \\
\hline 32 & PANIR & 9 & 1978 & $V C D-145 M$ & Vo28 & 80 & 3.22 & & \\
\hline 33 & PANIR & 9 & 1978 & $V C D-145 M$ & vo29 & 80 & 3.21 & & \\
\hline 34 & PANIR & 9 & 1978 & VCD-145M & Yoso & 80 & 3.22 & & \\
\hline 35 & PANIR & 9 & 1978 & $Y C D-145 M$ & Y031 & 80 & 3.22 & & \\
\hline 36 & PANIR & 9 & 1978 & VCD-145M & Vo32 & 80 & 3.22 & & \\
\hline 37 & PANIR & 9 & 1978 & $V C D-145 M$ & Y033 & 80 & 3.22 & & \\
\hline 38 & PANIR & 9 & 1978 & VCD-145M & V034 & 80 & 3.30 & & \\
\hline
\end{tabular}


TABLE II (page 2 of 3 ) VCD-145 Calibration Data - Sorted by Collimator Diameter

\begin{tabular}{|c|c|c|c|c|c|c|c|c|c|}
\hline Memo & Event name & Month & Year & Type & Serial & Collimator & \multicolumn{2}{|c|}{ Sensitivity } & \\
\hline entry & & & & name & Number & diameter & $1-\mathrm{mil}$ & 2-mil & Aver age \\
\hline sequence & & & & (as in memo) & & $(\mathrm{mm})$ & $(e-22)$ & $(e-22)$ & \\
\hline 40 & DIABLO HAWK & 10 & 1978 & VCD-145M & Y020 & 80 & 3.21 & & \\
\hline 42 & DIABLO HAWK & 10 & 1978 & VCD-145M & Y022 & 80 & 3.24 & & \\
\hline 44 & DIABLO HAMK & 10 & 1978 & VCD-145M & Yo25 & 80 & 3.21 & & \\
\hline 46 & DIABLO HAMK & 10 & 1978 & VCD-145M & yo26 & 80 & 3.22 & & \\
\hline 47 & QUARGEL & 11 & 1978 & VCD-145M & V035 & 80 & 3.18 & & \\
\hline 48 & QUARGEL & 11 & 1978 & YCD-145M & vos6 & 80 & 3.22 & & \\
\hline 49 & QUARGEL & 11 & 1978 & YCD-145M & vos? & 80 & 3.20 & & \\
\hline 50 & QUARGEL & 11 & 1978 & VCD-145M & Yose & 80 & 3.18 & & \\
\hline 51 & QUARGEL & 11 & 1978 & VCD-145M & vase & 80 & 3.20 & & \\
\hline 53 & FARM & 12 & 1978 & YCD-145M & $\mathrm{YO40}$ & 80 & 3.18 & & \\
\hline 54 & FARM & 12 & 1978 & VCD-145M & $\mathrm{V} 041$ & 80 & 3.15 & & \\
\hline 55 & FARM & 12 & 1978 & VCD-145M & V042 & 80 & 3.18 & & 3.20 \\
\hline 56 & FARM & 12 & 1978 & VCD-145M & Y043 & 80 & 3.20 & & $(80 \mathrm{~mm})$ \\
\hline 57 & FARM & 12 & 1978 & VCD-145M & V044 & 80 & 3.16 & & \\
\hline 58 & FARM & 12 & 1978 & VCD-145M & Yo45 & 80 & 3.20 & & \\
\hline 59 & FARM & 12 & 1978 & VCD-145M & Vo46 & 80 & 3.16 & & \\
\hline 60 & FARM & 12 & 1978 & VCD-145M & Y047 & 80 & 3.16 & & \\
\hline 61 & FARM & 12 & 1978 & VCD-145M & YO4B & 80 & 3.16 & & \\
\hline 63 & KLOSTER & 2 & 1979 & VCD-145M & Y050 & 80 & 3.13 & & \\
\hline 65 & KLOSTER & 2 & 1979 & VCD-145M & Yo51 & 80 & 3.13 & & \\
\hline 67 & KLOSTER & 2 & 1979 & VCD-145M & Yo52 & 80 & 3.14 & & \\
\hline 69 & KLOSTER & 2 & 1979 & VCD-145M & V053 & 80 & 3.18 & & \\
\hline 70 & PEPATO & 6 & 1979 & VCD-145M & vo22 & 80 & 3.22 & & \\
\hline 73 & PEPATO & 6 & 1979 & VCD-145M & Vo25 & 80 & 3.20 & & \\
\hline 74 & BURZET & 8 & 1979 & YCD-145M & Y042 & 80 & 3.20 & & \\
\hline 75 & BURZET & 8 & 1979 & VCD-145M & Yo55 & 80 & 3.20 & & \\
\hline 76 & BURZET & 8 & 1979 & VCD-145M & Vo56 & 80 & 3.19 & & \\
\hline 77 & PERA & 9 & 1979 & VCD-145M-1 & V053 & 80 & 3.20 & & \\
\hline 115 & LIPTAUUER & 4 & 1980 & VCD-145-1M & V049 & 85 & 3.14 & & 3.14 \\
\hline 52 & QUARGEL & 11 & 1978 & VCD-145M & Yo39 & 90 & 3.10 & & \\
\hline 116 & LIPTAUER & 4 & 1980 & VCD-145-1M & Yo49 & 90 & 3.12 & & 3.11 \\
\hline 91 & NORBO & 3 & 1980 & VCD-145-2M & Y013 & 60 & & 2.90 & \\
\hline 92 & NORBO & 3 & 1980 & VCD-145-2M & Y017 & 60 & & 2.88 & \\
\hline 93 & NORBO & 3 & 1980 & VCD-145-2M & Y021 & 60 & & 2.97 & \\
\hline 97 & NORBO & 3 & 1980 & VCD-145-2M & Yo73 & 60 & & 2.94 & \\
\hline 98 & NORBO & 3 & 1980 & VCD-145-2M & Yo75 & 60 & & 2.90 & \\
\hline 101 & NORBO & 3 & 1980 & $Y C D-145-2 M$ & Yo78 & 60 & & 2.87 & 2.89 \\
\hline 102 & NORBO & 3 & 1980 & VCD-145-2M & vo79 & 60 & & 2.83 & $(60-\mathrm{mm})$ \\
\hline 103 & COLWICK & 4 & 1980 & $V C D-145 M$ & Yo59 & 60 & & 2.85 & \\
\hline 105 & COLWICK & 4 & 1980 & $V C D-145 M$ & vose & 60 & & 2.86 & \\
\hline 107 & COLWICK & 4 & 1980 & VCD-145M & vos3 & 60 & & 2.86 & \\
\hline 111 & COLWICK & 4 & 1980 & VCD-145M & Y087 & 60 & & 2.88 & \\
\hline 78 & NESSEL & 9 & 1979 & VCD-145-2M & Yo60 & 80 & & 2.88 & \\
\hline 79 & NESSEL & 9 & 1979 & VCD-145-2M & Yo61 & 80 & & 2.90 & \\
\hline 80 & NESSEL & 9 & 1979 & VCD-145-2M & Yo62 & 80 & & 2.89 & \\
\hline 81 & NESSEL & 9 & 1979 & VCD-145-2M & vo63 & 80 & & 2.88 & \\
\hline 82 & NESSEL & 9 & 1979 & YCD-145-2M & vo64 & 80 & & 2.97 & \\
\hline 83 & NESSEL & 9 & 1979 & VCD-145-2M & Yo65 & 80 & & 2.95 & \\
\hline 84 & NESSEL & 9 & 1979 & VCD-145-2M & Yo66 & 80 & & 2.93 & \\
\hline
\end{tabular}


TABLE II (page 3 of 3 )

VCD-145 Calibration Data - Sorted by Collimator Diameter

\begin{tabular}{|c|c|c|c|c|c|c|c|c|c|}
\hline Memo & Event name & Month & Year & Type & Serial & \multirow{2}{*}{$\begin{array}{l}\text { Collimator } \\
\text { diameter }\end{array}$} & \multicolumn{2}{|c|}{ Sensitivity } & \multirow{3}{*}{ Average } \\
\hline entry & & & & name & Number & & 1-mil & 2-mil & \\
\hline sequence & & & & (as in memo) & & $(\mathrm{mm})$ & $(e-22)$ & $(e-22)$ & \\
\hline 87 & TARKO & 2 & 1980 & VCD-145-2M & V068 & 80 & & 2.95 & \\
\hline 88 & TARKO & 2 & 1980 & VCD-145-2M & V071 & 80 & & 2.95 & \\
\hline 89 & TARKO & 2 & 1980 & VCD-145-2M & vo72 & 80 & & 2.93 & \\
\hline 90 & TARKO & 2 & 1980 & VCD-145-2M & V074 & 80 & & 2.93 & 2.92 \\
\hline 95 & NORBO & 3 & 1980 & VCD-145-2M & V069 & 80 & & 2.95 & $(80-\mathrm{mm})$ \\
\hline 96 & NORBO & 3 & 1980 & VCD-145-2M & vo70 & 80 & & 2.95 & \\
\hline 99 & NORBO & 3 & 1980 & VCD-145-2M & Vo75 & 80 & & 2.91 & \\
\hline 100 & NORBO & 3 & 1980 & $V C D-145-2 M$ & Vo76 & 80 & & 2.93 & \\
\hline 104 & COLWICK & 4 & 1980 & VCD-145M & Y081 & 80 & & 2.90 & \\
\hline 106 & COLWICK & 4 & 1980 & VCD-145M & VoB2 & 80 & & 2.88 & \\
\hline 108 & COLWICK & 4 & 1980 & YCD-145M & V084 & 80 & & 2.90 & \\
\hline 109 & COLWICK & 4 & 1980 & YCD-145M & vo85 & 80 & & 2.90 & \\
\hline 110 & COLWICK & 4 & 1980 & $V C D-145 M$ & Vo86 & 80 & & 2.90 & \\
\hline 112 & COLWICK & 4 & 1980 & YCD-145M & Vo87 & 80 & & 2.92 & \\
\hline 117 & LIPTAUER & 4 & 1980 & VCD-145-2M & V062 & 85 & & 2.89 & 2.89 \\
\hline 85 & AZUL & 12 & 1979 & VCD-1 45-2M & V058 & 90 & & 2.85 & \\
\hline 86 & AZUL & 12 & 1979 & VCD-1 45-2M & V059 & 90 & & 2.85 & 2.89 \\
\hline 118 & LIPTAUER & 4 & 1980 & VCD-145-2M & V067 & 90 & & 2.96 & \\
\hline 113 & LIPTAUER & 4 & 1980 & VCD-1 45-2M & V015 & 95 & & 2.96 & \\
\hline 114 & LIPTAIJER & 4 & 1980 & VCD-145-2M & Vo20 & 95 & & 3.00 & 2.98 \\
\hline & & & & & & & & & \\
\hline NOTE *1: & This calibratio & did not & use mag & nets, and it is $r$ & th included & in the aver & yes belo & & \\
\hline & & & & & & & & & \\
\hline Comments & by Brent Davis & Sept 4 . & 2003: & & & & & & \\
\hline Four detec & tor 'type name & ' appea & $r$, but the & re are probabl & only two t & ypes in the & sual sen & 1-mil or & 2-mil \\
\hline mindowi. & There was pro & abbly an & i irregular & ity in the transi & on of nam & es used. & & & \\
\hline Detectors & in gener al there & not rewn & orked, so & the appearano & of a giver & serial numk & er with $k$ & th $1-$ mil a & \\
\hline 2-mil min & dons probably & means $t$ & hat the 2 & -mil version sim & y used an & extra 1-mil & sheet plz & ed in & \\
\hline front of & the original vac & um vine & dow. & & & & & & \\
\hline & & & & & & & & & \\
\hline Mean ser & nsitivities: & & 1-mil wir & ndows & & & $2-\mathrm{mil} w$ & ndoins & \\
\hline & Collimation & $\not 4$ & Average & std. Dev. & & Coll. & $\#$ & Average & std. Dey. \\
\hline & $60-\mathrm{mm}$ & 19 & 3.19 & 0.043 & & $60-\mathrm{mm}$ & 11 & 2.89 & 0.039 \\
\hline & $75-\mathrm{mm}$ & 10 & 3.26 & 0.017 & & $80-\mathrm{mm}$ & 21 & 2.92 & 0.023 \\
\hline & 80-mm & 47 & 3.20 & 0.033 & & $85-\mathrm{mm}$ & 1 & 2.89 & 0 \\
\hline & 85-mm & 1 & 3.14 & 0 & & $90-\mathrm{mm}$ & 3 & 2.89 & 0.052 \\
\hline & $90-\mathrm{mm}$ & 2 & 3.11 & 0.010 & & $95-\mathrm{mm}$ & 2 & 2.98 & 0.020 \\
\hline & & & & & & & & & \\
\hline RATIO: & 2-mil to $1-\mathrm{mil}$ & (same & diameter & & & & & & \\
\hline & $60-\mathrm{mm}$ dia & 0.905 & & & & & & & \\
\hline & 80-mm dia & 0.913 & & & & 1. $0 \mathrm{E}-22$ is & uppress & d in all & \\
\hline & $90-\mathrm{mm}$ & 0.928 & & & & sensitivit & $y$ values & eported. & \\
\hline & & & & & & & & & \\
\hline
\end{tabular}




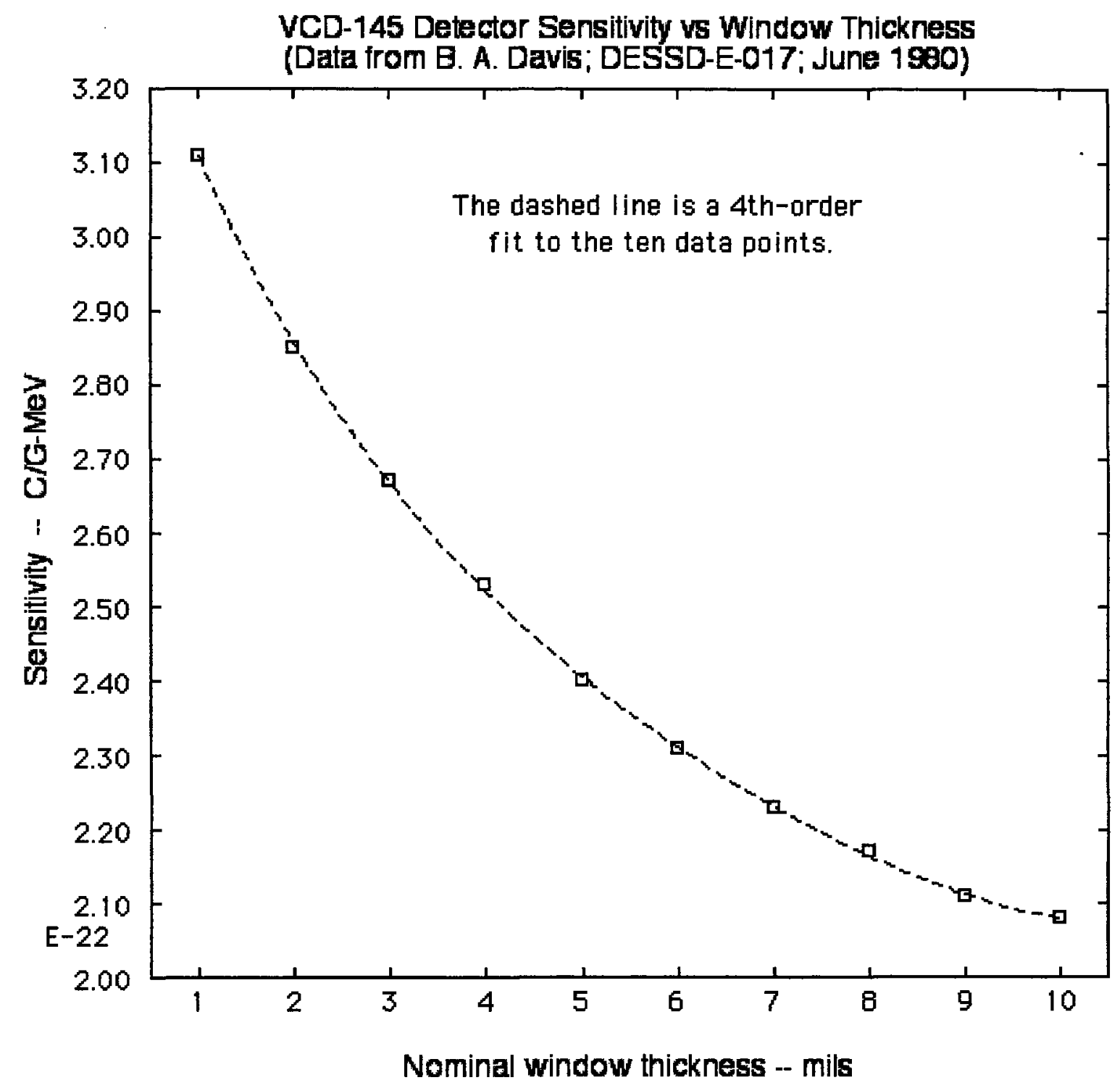

Figure 1. Variation of detector sensitivity with window thickness. 